\title{
Mucoadhesive drug delivery systems
}

\author{
Flávia Chiva Carvalho', Marcos Luciano Bruschi ${ }^{2}$, Raul Cesar Evangelista ${ }^{1,3}$, \\ Maria Palmira Daflon Gremião ${ }^{1,3, *}$
}

\begin{abstract}
${ }^{1}$ Pharmaceutical Sciences Postgraduate Program, School of Pharmaceutical Sciences, São Paulo State University, UNESP, ${ }^{2}$ Department of Pharmacy, State University of Maringá, UEM, ${ }^{3}$ Department of Drugs and Pharmaceuticals, School of Pharmaceutical Sciences, São Paulo State University, UNESP
\end{abstract}

\begin{abstract}
Drug actions can be improved by developing new drug delivery systems, such as the mucoadhesive system. These systems remain in close contact with the absorption tissue, the mucous membrane, releasing the drug at the action site leading to a bioavailability increase and both local and systemic effects. Mucoadhesion is currently explained by six theories: electronic, adsorption, wettability, diffusion, fracture and mechanical. Several in vitro and in vivo methodologies are proposed for studying its mechanisms. However, mucoadhesion is not yet well understood. The aim of this study was to review the mechanisms and theories involved in mucoadhesion, as well as to describe the most-used methodologies and polymers in mucoadhesive drug delivery systems.
\end{abstract}

Uniterms: Mucoadhesion. Bioadhesion. Mucoadhesive systems. Drugs/delivery.

O efeito de fármacos pode ser potencializado através do desenvolvimento de novos sistemas de liberação como os sistemas mucoadesivos. Estes sistemas permanecem em contato íntimo com o tecido de absorção, as mucosas, liberando o fármaco no local de ação, com o consequente aumento da biodisponibilidade, podendo promover efeitos locais e sistêmicos. A mucoadesão, atualmente, é explicada por seis teorias, a eletrônica, da adsorção, da molhabilidade, da difusão, da fratura e a mecânica. Para estudar seus mecanismos e quantificá-la, são propostas várias metodologias in vitro e in vivo. Porém, a mucoadesão ainda não é totalmente compreendida. Esse trabalho tem por objetivo revisar os mecanismos e as teorias envolvidas na mucoadesão, além de descrever as metodologias e os polímeros mais utilizados em sistemas mucoadesivos para liberação de fármacos.

Unitermos: Mucoadesão. Bioadesão. Sistemas mucoadesivos. Fármacos/liberação.

\section{INTRODUCTION}

The effect of a drug can now be reinforced as a result of the development of new release systems. Controlled release consists of techniques that make the active chemical agents available for a target, providing an adequate release rate and duration to produce the desired effect. The main controlled drug delivery systems currently available include matrices, pellets, floating systems, liposomes, microemulsions, liquid crystals, solid dispersions, nanosuspensions, transdermal systems, cyclodextrin inclusion complexes, osmotic pumps and bioadhesive systems (Wise, 2000).

*Correspondence: M. P. D. Gremião. School of Pharmaceutical Sciences UNESP. Rodovia Araraquara-Jaú, km 1 - 14801-902 - Araraquara - SP, Brazil. E-mail: pgremiao@fcfar.unesp.br
Bioadhesion can be defined as the state in which two materials, at least one of which is biological in nature, are maintained together for a prolonged time period by means of interfacial forces (Smart, 2005). During the 1980s, this concept began to be applied to drug delivery systems. It consists of the incorporation of adhesive molecules into some kind of pharmaceutical formulation intended to stay in close contact with the absorption tissue, releasing the drug near to the action site, thereby increasing its bioavailability and promoting local or systemic effects (Hägerström, 2003; Woodley, 2001). An extensive review on mucoadhesive systems was compiled by Andrews, Laverty and Jones (2008).

The potential use for mucoadhesive systems as drug carriers lies in its prolongation of the residence time at the absorption site, allowing intensified contact with the 
epithelial barrier (Hägerström, 2003). On the other hand, adhesion of preparations onto mucous membrane can be impaired by the mucociliary clearance system. This clearance, a natural defense mechanism of the body against the deposition of impurities onto the mucous membrane, can also remove the preparation. Thus, by using bioadhesive molecules, it is possible to retain the preparation at the action site and to direct the drug to a specific site or tissue. Other features associated with the development of controlled drug delivery systems using bioadhesive molecules include a decrease in drug administration frequency and an increase in patient compliance to the therapy (Woodley, 2001). Therefore, a bioadhesive system controlling drug release could improve the treatment of diseases, helping to maintain an effective concentration of the drug at the action site (Huang et al., 2000).

Mucous membrane is the main administration site for bioadhesive systems, although the need for new bioadhesive formulations for dermal administration has also been reported when prolonged cutaneous action is desired. A prolonged effect upon the dermal administration of creams, solutions, and lotions is unexpected, since such preparations can be easily removed from the skin by moisture, temperature, and physical movements (Shin et al., 2003).

Mucousl membranes of human organism are relatively permeable and allow fast drug absorption (Jasti, Li, Cleary, 2003). They are characterized by an epithelial layer whose surface is covered by mucus. The mucus contains glycoproteins, lipids, inorganic salts and $95 \%$ water by mass, making it a highly hydrated system. Mucin is the most important glycoprotein of mucus and is responsible for its structure. The main functions of mucus are protecting and lubricating the epithelium and other additional functions depending on the epithelium covered. Mucus thickness can vary from $50-450 \mu \mathrm{m}$ in the stomach to less than $1 \mu \mathrm{m}$ in the oral cavity (Smart, 2005). The mucous site most used for drug administration and absorption is gastrointestinal (Junginger, Thanou, Verhoef, 2002), but other routes, including nasal, ocular, buccal, vaginal, rectal, oral, and periodontal have also been studied (Bruschi et. al. 2008, Bruschi, 2007; Hägerström, 2003; Woodley, 2001).

Bioadhesive systems applied to mucous membrane are frequently defined as mucoadhesive, but the terms are interchangeable (Leung, Robinson, 1990). It is feasible to design a bio(muco)adhesive system in different dosage for$\mathrm{ms}$, since the properties of adhesion largely depend on the features of the material used in its preparation (Evangelista, 2006). Therefore, several conventional drug delivery systems already in use can become bioadhesive after redesign by including bioadhesive substances in their formulation.
This approach to confer Bioadhesion properties has been widely applied in the development of a number of drug delivery systems. Solid micro- and nano-particulate systems based on chitosan and derivatives have been the focus of several studies (Bravo-Osuna et al., 2007; Wittaya-Areekul, Kruenate, Prahsarn, 2006): microemulsions are thermodynamically stable and isotropic liquid systems, which allow the incorporation of bioadhesive molecules, such as polycarbophil (Vyas et al., 2006); colloidal dispersions of bioadhesive polymers frequently used in preparations for oral hygiene (Kockisch et al., 2001); semi-solid systems, as liquid crystalline mesophases (Bruschi et al., 2007, 2008) and hydrogels (Bruschi et al., 2007; Huang et al., 2000), which can increase the contact time between preparation and mucous membrane after they undergo in situ gelation.

There are a number of materials used for developing such systems. The most studied materials are the polymers derived from polyacrylic acid, such as polycarbophil and carbomers, polymers derived from cellulose, such as hydroxyethylcellulose and carboxymethylcellulose, alginates, chitosan and derivatives and more recently, lectins and their derivatives (Grabovac, Guggi, BernkopSchnürch, 2005; Smart, 2005).

Although studies on the mechanisms involved in mucoadhesion and the development of novel mucoadhesive systems and polymers have evolved over the last twenty years, mucoadhesion is not yet fully understood. Quantitative and qualitative techniques are still treated separately. The aim of this study was to systematically review the mechanisms and theories involving mucoadhesion, as well as to describe the methods and polymers most used in mucoadhesive systems for drug delivery.

\section{MECHANISMS OF MUCOADHESION}

The mechanism of adhesion of certain macromolecules to the surface of a mucous tissue is not well understood yet. The mucoadhesive must spread over the substrate to initiate close contact and increase surface contact, promoting the diffusion of its chains within the mucus. Attraction and repulsion forces arise and, for a mucoadhesive to be successful, the attraction forces must dominate. Each step can be facilitated by the nature of the dosage form and how it is administered. For example, a partially hydrated polymer can be adsorbed by the substrate because of the attraction by the surface water (Lee, Park, Robinson et al., 2000).

Thus, the mechanism of mucoadhesion is generally divided in two steps, the contact stage and the consolidation stage (Figure 1). The first stage is characterized by 
the contact between the mucoadhesive and the mucous membrane, with spreading and swelling of the formulation, initiating its deep contact with the mucus layer (Hägerstrom, 2003). In some cases, such as for ocular or vaginal formulations, the delivery system is mechanically attached over the membrane. In other cases, the deposition is promoted by the aerodynamics of the organ to which the system is administered, such as for the nasal route. On the other hand, in the gastrointestinal tract direct formulation attachment over the mucous membrane is not feasible. Peristaltic motions can contribute to this contact, but there is little evidence in the literature showing appropriate adhesion. Additionally, an undesirable adhesion in the esophagus can occur. In these cases, mucoadhesion can be explained by peristalsis, the motion of organic fluids in the organ cavity, or by Brownian motion. If the particle approaches the mucous surface, it will come into contact with repulsive forces (osmotic pressure, electrostatic repulsion, etc.) and attractive forces (van der Waals forces and electrostatic attraction). Therefore, the particle must overcome this repulsive barrier (Smart, 2005).

In the consolidation step (Figure 1), the mucoadhesive materials are activated by the presence of moisture. Moisture plasticizes the system, allowing the mucoadhesive molecules to break free and to link up by weak van der Waals and hydrogen bonds (Smart, 2005). Essentially, there are two theories explaining the consolidation step: the diffusion theory and the dehydration theory. According to diffusion theory, the mucoadhesive molecules and the glycoproteins of the mucus mutually interact by means of interpenetration of their chains and the building of secondary bonds (Smart, 2005). For this to take place the mucoadhesive device has features favoring both chemical and mechanical interactions. For example, molecules with hydrogen bonds building groups $(-\mathrm{OH},-\mathrm{COOH})$, with an anionic surface charge, high molecular weight, flexible chains and surface-active properties, which induct its spre-

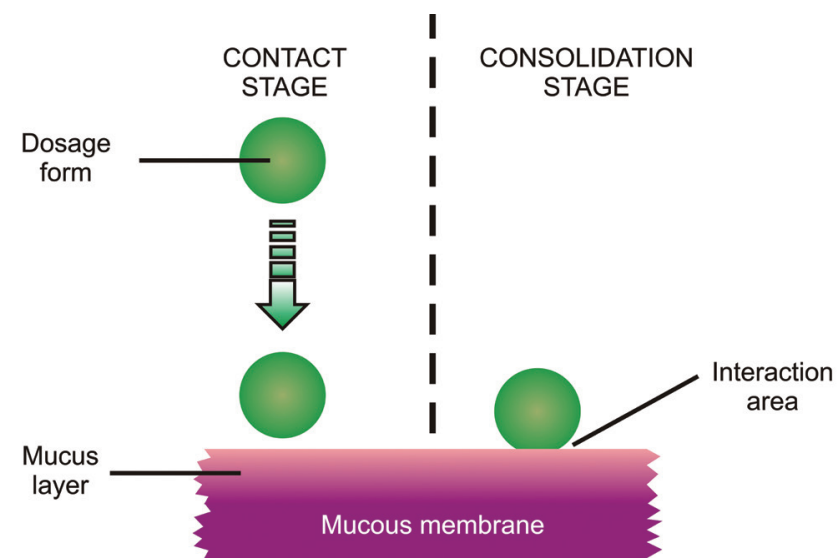

FIGURE 1 - The two steps of the mucoadhesion process. ad throughout the mucus layer, can present mucoadhesive properties (Mathiowitz, Chickering, Lehr, 1999).

According to dehydration theory, materials that are able to readily gelify in an aqueous environment, when placed in contact with the mucus can cause its dehydration due to the difference of osmotic pressure. The difference in concentration gradient draws the water into the formulation until the osmotic balance is reached. This process leads to the mixture of formulation and mucus and can thus increase contact time with the mucous membrane. Therefore, it is the water motion that leads to the consolidation of the adhesive bond, and not the interpenetration of macromolecular chains. However, the dehydration theory is not applicable for solid formulations or highly hydrated forms (Smart, 2005).

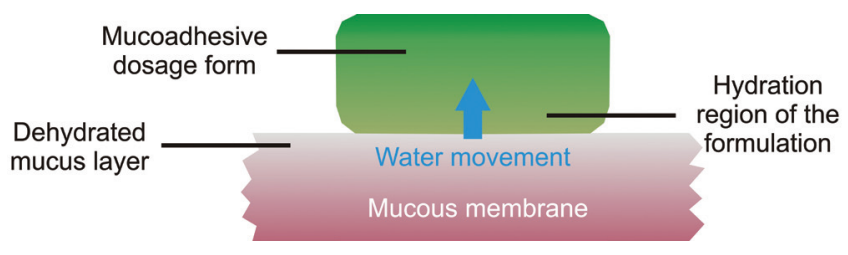

FIGURE 2 - Dehydration theory of mucoadhesion.

\section{MUCOADHESION THEORIES}

Although the chemical and physical basis of mucoadhesion are not yet well understood, there are six classical theories adapted from studies on the performance of several materials and polymer-polymer adhesion which explain the phenomenon (Hägerström, 2003; Huang et al., 2000; Smart, 2005).

\section{Electronic theory}

Electronic theory is based on the premise that both mucoadhesive and biological materials possess opposing electrical charges. Thus, when both materials come into contact, they transfer electrons leading to the building of a double electronic layer at the interface, where the attractive forces within this electronic double layer determines the mucoadhesive strength (Mathiowitz, Chickering, Lehr, 1999).

\section{Adsorption theory}

According to the adsorption theory, the mucoadhesive device adheres to the mucus by secondary chemical interactions, such as in van der Waals and hydrogen bonds, electrostatic attraction or hydrophobic interactions. For example, hydrogen bonds are the prevalent interfacial for- 
ces in polymers containing carboxyl groups (Hägerström, 2003; Huang et al., 2000; Lee, Park, Robinson, 2000; Smart, 2005). Such forces have been considered the most important in the adhesive interaction phenomenon (Smart, 2005 ) because, although they are individually weak, a great number of interactions can result in an intense global adhesion (Mathiowitz, Chickering, Lehr, 1999).

\section{Wetting theory}

The wetting theory applies to liquid systems which present affinity to the surface in order to spread over it. This affinity can be found by using measuring techniques such as the contact angle. The general rule states that the lower the contact angle then the greater the affinity (Figure $3)$. The contact angle should be equal or close to zero to provide adequate spreadability (Mathiowitz, Chickering, Lehr, 1999).

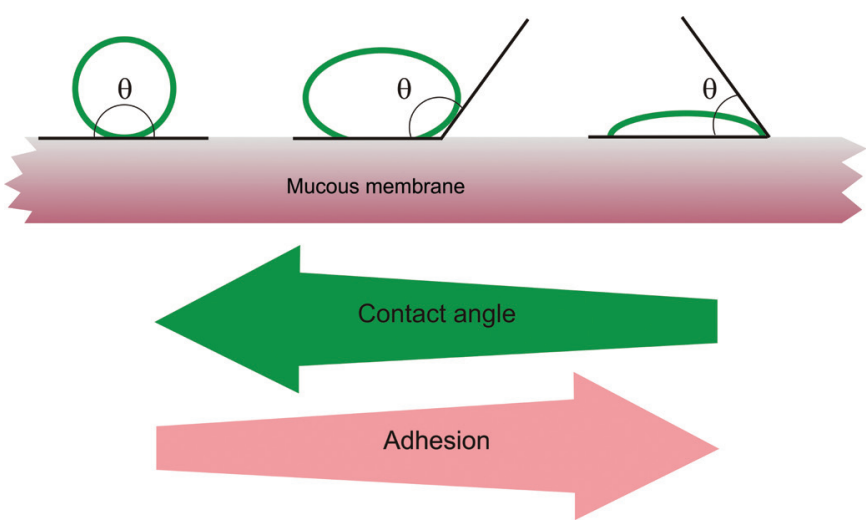

FIGURE 3 - Schematic diagram showing influence of contact angle between device and mucous membrane on bioadhesion.

The spreadability coefficient, $S_{A B}$, can be calculated from the difference between the surface energies $\gamma_{B}$ and $\gamma_{A}$ and the interfacial energy $\gamma_{A B}$, as indicated in equation (1) (Smart, 2005).

$S_{A B}=\gamma_{B}-\gamma_{A}-\gamma_{A B}$

The greater the individual surface energy of mucus and device in relation to the interfacial energy, the greater the adhesion work, $W_{A}$, i.e. the greater the energy needed to separate the two phases (Smart, 2005).

$$
W_{A}=\gamma_{A}+\gamma_{B}-\gamma_{A B}
$$

\section{Diffusion theory}

Diffusion theory describes the interpenetration of both polymer and mucin chains to a sufficient depth to create a semi-permanent adhesive bond (Figure 4). It is believed that the adhesion force increases with the degree of penetration of the polymer chains (Mathiowitz, Chickering, Lehr, 1999). This penetration rate depends on the diffusion coefficient, flexibility and nature of the mucoadhesive chains, mobility and contact time (Hägerström, 2003; Huang et al., 2000; Lee, Park, Robinson, 2000; Smart, 2005). According to the literature, the depth of interpenetration required to produce an efficient bioadhesive bond lies in the range 0.2-0.5 $\mu \mathrm{m}$. This interpenetration depth of polymer and mucin chains can be estimated by equation 3:

$l=\left(t D_{b}\right)^{1 / 2}$

where $t$ is the contact time, and $D_{b}$ is the diffusion coefficient of the mucoadhesive material in the mucus. The adhesion strength for a polymer is reached when the depth of penetration is approximately equivalent to the polymer chain size (Mathiowitz Chickering, Lehr, 1999).

In order for diffusion to occur, it is important that the components involved have good mutual solubility, that is, both the bioadhesive and the mucus have similar chemical structures. The greater the structural similarity, the better the mucoadhesive bond (Mathiowitz Chickering, Lehr, 1999).

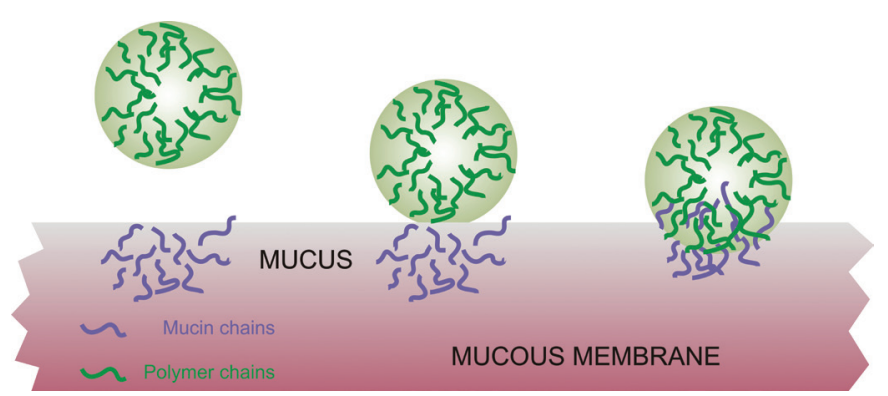

FIGURE 4 - Secondary interactions resulting from interdiffusion of polymer chains of bioadhesive device and of mucus.

\section{Fracture theory}

This is perhaps the most-used theory in studies on the mechanical measurement of mucoadhesion (Mathiowitz Chickering, Lehr, 1999). It analyses the force required to separate two surfaces after adhesion is established (Hägerström, 2003; Smart, 2005). This force, $s_{m}$, is frequently calculated in tests of resistance to rupture by the ratio of the maximal detachment force, $F_{m}$, and the total surface area, $A_{0}$, involved in the adhesive interaction (equation 4 ): 
$S_{m}=\frac{F_{m}}{A_{0}}$

In a single component uniform system, the fracture force, $s_{i}$, which is equivalent to the maximal rupture tensile strength, $s_{m}$, is proportional to the fracture energy $\left(g_{c}\right)$, for Young's module $(E)$ and to the critical breaking length $(c)$ for the fracture site, as described in equation 5 :

$s_{f} \sim\left(\frac{g_{c} E}{c}\right)^{1 / 2}$

Fracture energy $\left(g_{c}\right)$ can be obtained from the reversible adhesion work, $W_{r}$ (energy required to produce new fractured surfaces), and the irreversible adhesion work, $W_{i}$ (work of plastic deformation provoked by the removal of a proof tip until the disruption of the adhesive bond), and both values are expressed as units of fracture surface $\left(A_{f}\right)$.

$g_{c}=W_{r}+W_{i}$

The elastic module of the system $(E)$ is related to the stress $(s)$ and to the shear $(e)$ by Hooke's law:

$$
E=\left[\frac{\sigma}{\varepsilon}\right]_{\varepsilon \rightarrow 0}=\left[\frac{F / A_{0}}{\Delta l / l_{0}}\right]_{\Delta l \rightarrow o}
$$

In equation 7 , the stress is the ratio between force $(F)$ and area $\left(A_{0}\right)$, and shear is given by the ratio between the variation of system thickness $(\Delta l)$ and the original thickness $\left(l_{0}\right)$.

A criticism of this analysis is that the system under investigation must have known physical dimensions and should be constituted by a single and uniform material. In virtue of this, the relationship obtained cannot be applied to analyze the fracture site of a multiple component bioadhesive. In this case, the equation should be expanded to accommodate elastic dimensions and modules for each component. Besides, it must be considered that a failure of adhesion will occur at the bioadhesive interface. However, it has been demonstrated that the rupture rarely occurs at the surface, but near it (Mathiowitz Chickering; Lehr, 1999) or at the weakest point, which can be the interface itself, the mucus layer or the hydrated region of the mucus, as illustrated in Figure 5 (Smart, 2005).

Since the fracture theory is concerned only with the force required to separate the parts, it does not take into ac-

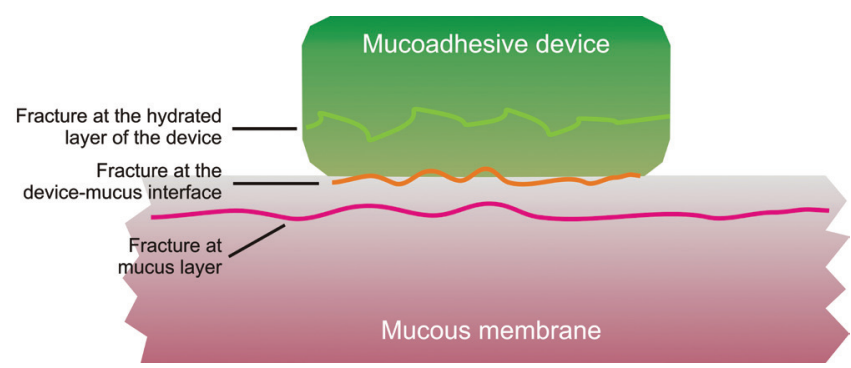

FIGURE 5 - Regions where the mucoadhesive bond rupture can occur.

count the interpenetration or diffusion of polymer chains. Consequently, it is appropriate for use in the calculations for rigid or semi-rigid bioadhesive materials, in which the polymer chains do not penetrate into the mucus layer (Mathiowitz Chickering, Lehr, 1999).

\section{Mechanical theory}

Mechanical theory considers adhesion to be due to the filling of the irregularities on a rough surface by a mucoadhesive liquid. Moreover, such roughness increases the interfacial area available to interactions thereby aiding dissipating energy and can be considered the most important phenomenon of the process (Peppas, Sahlin, 1996; Smart, 2005).

It is unlikely that the mucoadhesion process is the same for all cases and therefore it cannot be described by a single theory. In fact, all theories are relevant to identify the important process variables (Lee, Park, Robinson, 2000).

The mechanisms governing mucoadhesion are also determined by the intrinsic properties of the formulation and by the environment in which it is applied (Lee, Park, Robinson, 2000). Intrinsic factors of the polymer are related to its molecular weight, concentration and chain flexibility. For linear polymers, mucoadhesion increases with molecular weight, but the same relationship does not hold for nonlinear polymers. It has been shown that more concentrated mucoadhesive dispersions are retained on the mucous membrane for longer periods, as in the case of systems formed by in situ gelification. After application, such systems spread easily, since they present rheological properties of a liquid, but gelify as they come into contact the absorption site, thus preventing their rapid removal. Chain flexibility is critical to consolidate the interpenetration between formulation and mucus (Lee, Park, Robinson, 2000).

Environment-related factors include $\mathrm{pH}$, initial contact time, swelling and physiological variations. The $\mathrm{pH}$ can influence the formation of ionizable groups in polymers as well as the formation of charges on the mucus 
surface. Contact time between mucoadhesive and mucus layer determines the extent of chain interpenetration. Super-hydration of the system can lead to build up of mucilage without adhesion. The thickness of the mucus layer can vary from 50 to $450 \mu \mathrm{m}$ in the stomach (Smart, $2005)$ to less than $1 \mu \mathrm{m}$ in the oral cavity. Other physiological variations can also occur with diseases (Lee, Park, Robinson, 2000).

None of these mechanisms or theories alone can explain the mucoadhesion which occurs in an array of different situations. However, the understanding of these mechanisms in each instance can help toward the development of new mucoadhesive products (Smart, 2005).

\section{MUCOADHESIVE MATERIALS}

The first study presenting the use of a mucoadhesive material was conducted by Nagai, and proposed an improved treatment for stomatitis by using adhesive tablets. Additionally, an increase in the systemic bioavailability of insulin was observed in the form of bioadhesive powder after nasal administration in dogs (Nagai et al.,1984; Nagai, 1985). Thereafter, bioadhesive materials have been used as absorption promoters for several administration routes. Earlier experiments were also done with known polymers available on the market, such as polyacrylic acids. Currently, the latest research is seeking to develop materials that direct the formulation more specifically to the action site and that can offer other functions besides mucoadhesion such as control over permeation within epithelial tissues, and inactivation of enzymes which can compromise release system action (Hägerström, 2003).

\section{First generation mucoadhesive materials}

These materials are natural or synthetic hydrophilic molecules containing numerous organic functions that generate hydrogen bonds such as carboxyl, hydroxyl and amino groups, which do not adhere specifically onto several surfaces. The very first use of mucoadhesive was as denture fixers and the most known examples are carbomers, chitosans, alginates and cellulose derivatives. They can be incorporated into solid formulations, such as tablets, transdermal adhesives and microparticles, and into semisolid formulations including gels, ointments, pastes and suppositories (Smart, 2005). These polymers can be subdivided into three classes: cationic, anionic and nonionic.

Cationic molecules can interact with the mucus surface, since it is negatively charged at physiological $\mathrm{pH}$. Mucoadhesion of cationic polymers such as chitosan, occurs because of the electrostatic interactions of their amino groups with the sialic groups of mucin in the mucus layer. Chitosan is a semi-synthetic polymer obtained by the deacetylation of chitin and has been extensively investigated as a drug delivery mucoadhesive systems (Woodley, 2001). Studies have demonstrated that chitosan can promote the absorption of hydrophilic molecules by the structural reorganization of the proteins associated to the intercellular junctions (Bravo-Osuna et al., 2007). The presence of chitosan at the surface of nanoparticles clearly increased their intestinal mucoadhesive behavior in rats (Bravo-Osuna et al., 2007). Bocataj et al. (2003) demonstrated in their studies that chitosan showed higher mucoadhesion than carboxymethylcellulose and polycarbophil.

In contrast, synthetic polymers derived from polyacrylic acid (carbomers) are negatively charged but are also mucoadhesive. In this case, mucoadhesion results from physical-chemical processes, such as hydrophobic interactions, hydrogen and van der Waals bonds, which are controlled by $\mathrm{pH}$ and ionic composition (Woodley, 2001). Polyacrylic acid hydrogels have been extensively studied as mucoadhesive systems. Their chains are flexible and have non-abrasive characteristics when in the partially hydrated state, which decreases the tissue damage caused by friction when they come into contact (Huang et al., 2000). The majority of polyacrylic acid derivatives are not water soluble, such as polycarbophil, but form viscous gels when hydrated (Woodley, 2001). Other examples of anionic polymers are carboxymethylcellulose and alginates. The alginates, negatively charged polysaccharides, are widely used in the production of microparticles and are frequently reported as polyanionic mucoadhesive polymers (Wittaya-Areekul, Kruenate, Prahsarn, 2006).

Nonionic polymers, including hydroxypropylmethylcellulose, hydroxyethylcellulose and methylcellulose, present weaker mucoadhesion force compared to anionic polymers (Mortazavi, Moghimi, 2003).

There is a new class of substances being identified as bioadhesive. This class consists of ester groups of fatty acids, such as glyceryl monooleate and glyceryl monolinoleate, able to build liquid crystals which in turn can act as controlled release systems. These fatty acids build lyotropic liquid crystalline mesophases in the presence of water at body temperature. Liquid crystals can be considered structures of micelles ordered in a molecular arrangement characterized by alternate hydrophobic and hydrophilic regions. Different liquid-crystalline forms including lamellar, hexagonal, and cubic can be built as the surfactant concentration increases (Malmsten, 2002). Cubic phase favors the controlled release of drugs, since it has a structure made up of tridimensional curved lipid 
bilayers, separated by congruent water channels. This structure has the appearance of highly viscous transparent gel. Due to this relatively high viscosity, it is difficult to administer on any mucous membrane. In order to circumvent the administration problems, a less viscous mesophase, e.g., the lamellar phase, can be used. In these instances this phase is considered a precursor of the cubic phase. In the case of lyotropic mesophases, the precursor absorbs water in situ and spontaneously builds the cubic phase (Bruschi et al., 2007; Nielsen, Schubert, Hansen, 1998).

Some hydrogels do not build liquid crystals but are able to gelify in situ after exposure to an external stimulus. These are the so-called environmental sensitive polymers and are classified as thermosensitive, e.g. poloxamers and carbomers (Bruschi et al., 2007; Park et al., 2001), $\mathrm{pH}$ sensitive, e.g. polyacrylic acid, presenting increased viscosity at higher $\mathrm{pH}$ values, glucose sensitive, e.g. polymers linked to concavalin A, electric signal sensitive e.g. polymethacrylic acid, light sensitive, like hyaluronic acid (Qiu, Park, 2001) or ionic concentration sensitive, such as gellan gum (Hagerstrom et al., 2000). All these stimuli are found in the organism, making these polymers of great potential for use in the design of controlled release systems (Qiu, Park, 2001).

Mucoadhesion for gels formed by both liquid crystals and by environmental sensitive polymers can be explained by their rheological properties. These properties decrease the mucociliar clearance and increase the contact time of the formulation with the mucous membrane (Bruschi et al., 2007; Nielsen, Schubert, Hansen, 1998).

\section{Second generation mucoadhesive materials}

Studies on novel mucoadhesive systems involve the use of multifunctional materials. An ideal polymer should exhibit the ability to incorporate both hydrophilic and lipophilic drugs, show mucoadhesive properties in its solid and liquid forms, inhibit local enzymes or promote absorption, be specific for a particular cellular area or site, stimulate endocytosis and finally to have a broad safety range (Lee, Park, Robinson, 2000).

These novel multifunctional mucoadhesive systems are classified as second generation polymers (Lee, Park, Robinson, 2000). They are an alternative to non-specific bioadhesives (Smart, 2005) because they bind or adhere to specific chemical structures on the cell or mucus surface. Good examples of these molecules are lectins, invasins, fimbrial proteins (Woodley, 2001), antibodies (Chowdary, Rao, 2004), and those obtained by the addition of thiol groups to known molecules (Bravo-Osuna et al., 2007).

Lectins are immunogenic vegetal glycoproteins that specifically recognize sugar molecules. They are able to non-covalently bind to glycosilated components of the cellular membrane but not of the mucus, and adhesion can therefore be called cytoadhesion. Through the transmission of a cellular signal, this specific bond can result not only in bioadhesion but also in cellular internalization by different lysosomal and non-lysosomal mechanisms (Lehr, 2000). The most commonly found lectins are those isolated from Abrus precatroius, Agaricus bisporus, Anguilla anguilla, Arachis hypogaea, Pandeiraea simplicifolia, and Bauhinia purpurea (Chowdary, Rao, 2004).

Bacterial invasins are proteins from the membrane of Yersinia pseudotuberculosis that stimulate fagocytosis at cellular membrane through linkage with integrin receptors (Chowdary, Rao, 2004; Lehr, 2000; Woodley, 2001).

Bacterial fimbrial proteins are able to adhere to the epithelial surface of erythrocytes. This adhesion is related to the pathogenicity of the bacteria. Bacterial adhesive factors can be an efficient mechanism of improving adhesion of mucoadhesive agents used in release systems (Chowdary, Rao, 2004).

Antibodies can be produced against selected molecules present on the mucus surface. Due to their high specificity, antibodies can be a rational choice as polymeric ligand in the development of site-specific mucoadhesives. This strategy can be useful for instance, in drugs targeting tumor tissues (Chowdary, Rao, 2004).

Thiolated polymers are obtained by the addition of conjugated sulfidryl groups (Grabovac, Guggi, BernkopSchnürch, 2005). Bravo-Osuna et al. (2007) showed that thiolated chitosan increased mucoadhesive properties due to formation of disulfide bridges with cystein domains of glycoproteins of the mucus. Additionally, these products promoted mucus permeation by a mechanism of glutathione regeneration. Finally, they possess antiprotease activity due to their binding ability with divalent cations, such as zinc and magnesium, which are co-factors for many proteases. All these characteristics make thiolated chitosan a promising material for administering peptides and proteins in mucous membrane (Bravo-Osuna et al., 2007). Another study, carried out by Grabovac, Guggi, and Bernkop-Schnürch (2005) established a ranking of the most studied polymers, showing that both thiolated chitosan and polycarbophil are the most mucoadhesive.

Currently, the addition of elements of sensitization and recognition continue being used for the design of polymers with more intelligent mechanisms of mucoadhesion. By binding functional groups within polymer chains, hydrogels can be made more sensitive to surrounding environmental conditions like temperature, moisture, $\mathrm{pH}$, electrical fields and ionic forces (Peppas, Huang, 2004). 
Huang et al. (2000) proposed a mechanism in which units of the release system can specifically bind at the target surface. Certain amino acid sequences have complementary chains at mucous membrane and cellular surface. On contact with the mucous membrane, they can promote adhesion by binding to specific glycoproteins on this surface. Using this same mechanism, in the case of some diseases, changes occur in the glycoproteins, which can be attacked by complementary amino acid sequences linked to a release system, therefore increasing the affinity for diseased cells. The major problem with this strategy is finding the glycoproteins and their alterations in case of diseases (Huang et al., 2000).

With the advent of more intelligent mucoadhesive materials, it is possible to offer a unique carrying characteristic for many drugs (Huang et al., 2000). These can be designed for adhering onto any mucous membrane, for example ocular, buccal, respiratory, urinary, or gastrointestinal etc. Mucoadhesive materials can improve bioavailability, drug absorption and transport while reducing undesirable systemic effects. In summary, with these materials it is possible to develop novel systems for drugs currently used in therapy and to obtain new products at low cost.

\section{METHODS OF ANALYZING MUCOADHE- SION}

No technology has still been developed specifically to analyze mucoadhesion. Most of the tests available were adapted from other preexisting techniques but are useful and necessary for selecting the promising candidates as mucoadhesives as well as in elucidating their mechanisms of action.

\section{In vitro and ex vivo tests}

In vitro/ex vivo tests are important in the development of a controlled release bioadhesive system because they contribute to studies of permeation, release, compatibility, mechanical and physical stability, superficial interaction between formulation and mucous membrane and strength of the bioadhesive bond. These tests can simulate a number of administration routes including oral, buccal, periodontal, nasal, gastrointestinal, vaginal and rectal. The in vitro and ex vivo tests most prevalent in the literature are reported below.

\section{Techniques utilizing gut sac of rats}

The everted gut sac technique is an example of an ex vivo method. It has been used since 1954 to study in- testinal transport. Santos et al. (1999) applied this method on mucoadhesion assays. It is easy to reproduce and can be performed in almost all laboratories. Figure 6 schematically represents the technique. A segment of intestinal tissue is removed from the rat, everted, and one of its ends sutured and filled with saline. The sacs are introduced into tubes containing the system under analysis at known concentrations, stirred, incubated and then removed. The percent adhesion rate of the release system onto the sac is determined by subtracting the residual mass from the initial mass (Santos et al., 1999).

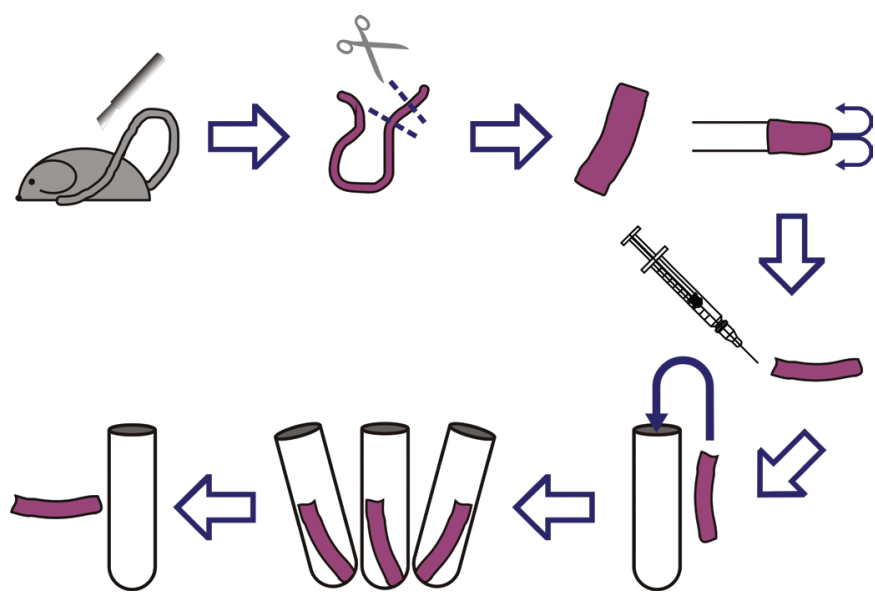

FIGURE 6 - Everted gut sac procedure.

Other techniques use non-everted gut sac. Takeuchi et al. (2005) filled rats' intestines with liposome suspensions. The sacs were sealed and incubated in saline. After a stipulated time, the number of liposomes adhered before $\left(N_{0}\right)$ and after $\left(N_{s}\right)$ incubation was assessed with a coulter counter and the percent mucoadhesive was expressed by equation 8 (Takeuchi et al., 2005).

$\%$ adhesive $=\left(\frac{N_{0}-N_{s}}{N_{0}}\right) \times 100$

The mucoadhesive effect of a system can also be evaluated by increases in gastrointestinal transit. Goto et al., 2006 incorporated fluorescent tracers into a system and quantified them by fluorescence spectroscopy in the stomach and intestinal mucus as a function of time.

\section{Tests measuring mucoadhesive strength}

Most in vitro/ex vivo methodologies found in the literature are based on the evaluation of mucoadhesive strength, that is, the force required to break the binding between the model membrane and the mucoadhesive. 
Depending on the direction in which the mucoadhesive is separated from the substrate, is it possible to obtain the detachment, shear, and rupture tensile strengths (Hägerström, 2003), as indicated in Figure 7.
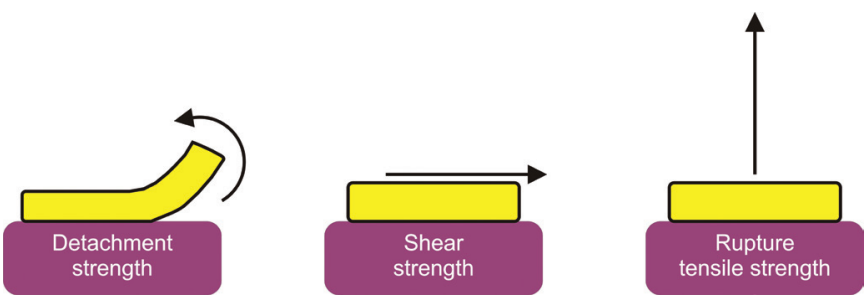

FIGURE 7 - Different forces evaluated in mucoadhesion tests.

The force most frequently evaluated in such tests is rupture tensile strength (Bromberg et al., 2004; Bruschi et al., 2007; Hägerström, 2003). Generally, the equipment used is a texture analyzer (Figure 8) or a universal testing machine. In this test, the force required to remove the formulation from a model membrane is measured, which can be a disc composed of mucin (Bruschi et al., 2007), a piece of animal mucous membrane, generally porcine nasal mucus (Hägerström, 2003) or intestinal mucus from rats (Bromberg et al., 2004). Based on results, a force-distance curve can be plotted which yields the force required to detach the mucin disc from the surface with the formulation (Bruschi et al., 2007), the tensile work (area under the curve during the detachment process), the peak force and the deformation to failure (Hägerström, 2003). This method is more frequently used to analyze solid systems like microspheres (Chowdary, Rao, 2004), although there are also studies on semi-solid materials (Bromberg et al., 2004; Bruschi et al., 2007).

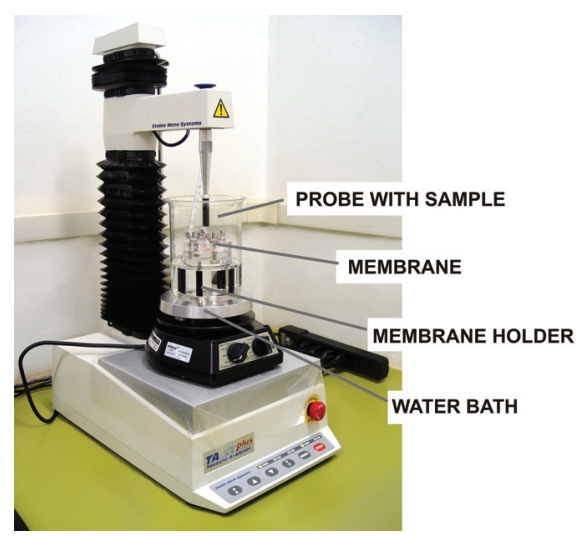

FIGURE 8 - Bioadhesion test using the texture analyzer.

In addition to rupture tensile strength, the texture analyzer can also, as inferred by its name, evaluate the texture of the formulations and assess other mechanical properties of the system. A mobile arm containing an analytical probe forces down into a sample held in a flask placed on the equipment's platform. Speed rate, time and depth are preset. From the resulting force-time and forcedistance plots, it is possible to calculate the hardness (force required to reach a given deformation), compressibility (work required to deform the product during the compression), and adhesiveness (work required to overcome the attraction forces between the surfaces of sample and probe). Using this technique, it is possible to perform a previous evaluation of the material's adhesive capacity, evidencing mucoadhesion properties (Bruschi, 2006).

Mucoadhesion strength can also be measured in terms of shear strength. This test measures the force required to separate two parallel glass slides covered with the polymer and with a mucus film (Bruschi, Freitas, 2005; Chowdary, Rao, 2004). This can also be done using Wilhemy's model (Figure 9), in which a glass plate is suspended by a microforce balance and immersed in a sample of mucus under controlled temperature. The force required to pull the plate out of the sample is then measured under constant experimental conditions (Ahuja, Khar, Ali, 1997). Although measures taken by this method are reproducible, the technique involves no biological tissue and therefore does not provide a realistic simulation of biological conditions (Wong, Yuen, Peh, 1999).

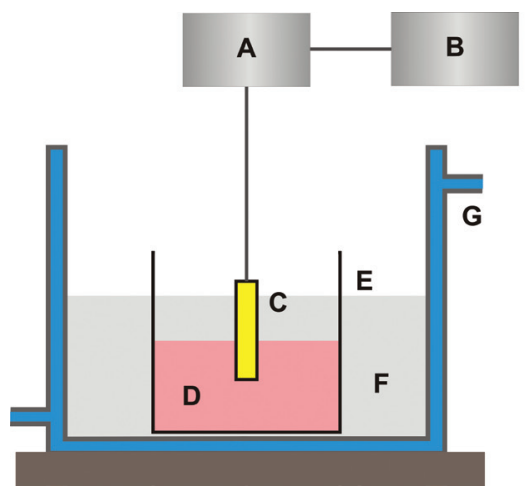
A - Microforce balance B - Recorder C - Glass plate D - Homogeneized mucus E - Glass recipient F - Water bath G - Water circulation

FIGURE 9 - Apparatus to determine mucoadhesion in vitro, using Wilhemy's technique.

Wilhemy's plate technique, or the microforce balance technique, can also be modified in order to measure the specific adhesion force of microparticles (Chowdary, Rao, 2004; Hägerström, 2003). This involves the use of a microtensiometer and a microforce balance (Figure 10) and is specific, yielding both contact angle and surface tension. The mucous membrane is placed in a small mobile chamber with both $\mathrm{pH}$ and physiological temperature controlled. A unique microsphere is attached by a thread to the stationary microbalance. The chamber with the mucous 


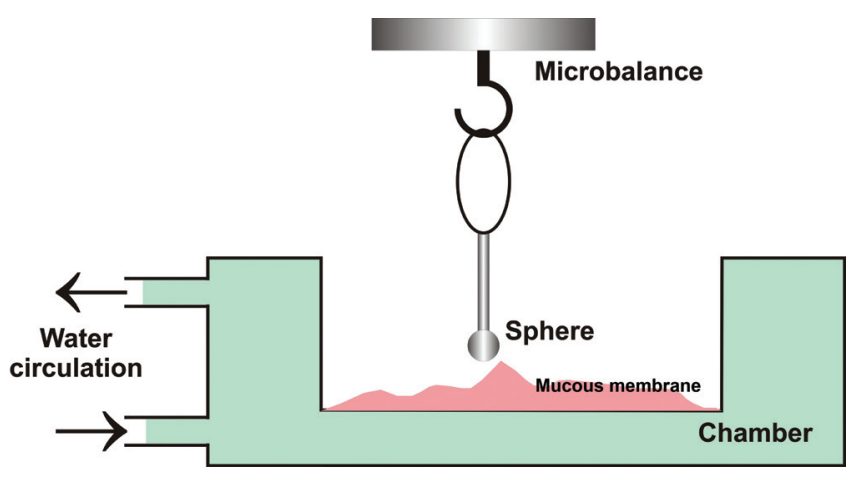

FIGURE 10 - Microbalance method for measuring mucoadhesion.

membrane is raised until it comes into contact with the microsphere and, after contact time, is lowered back to the initial position (Mathiowitz, Chickering, Lehr, 1999).

Following the trajectory, and with the aid of software, results can be obtained for several parameters such as fracture strength, deformation and rupture tensile strength, from a load versus deformation curve, as shown in Figure 11 (Mathiowitz, Chickering, Lehr, 1999).

a)

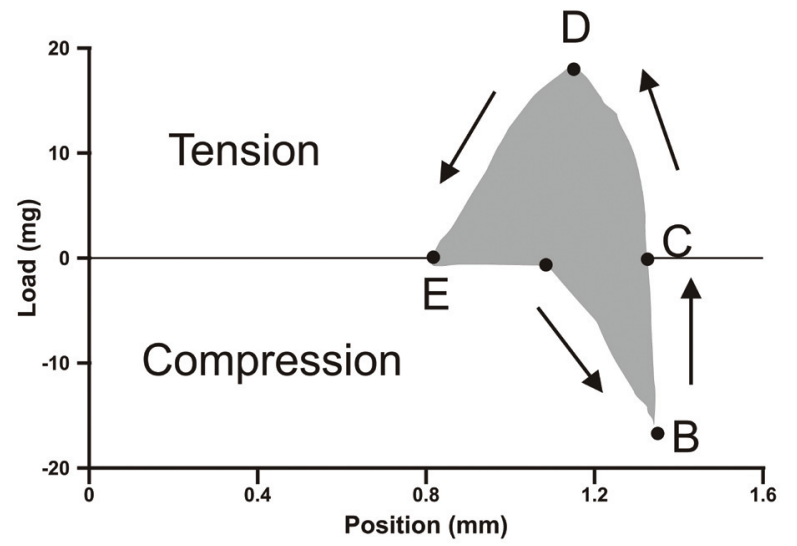

b)

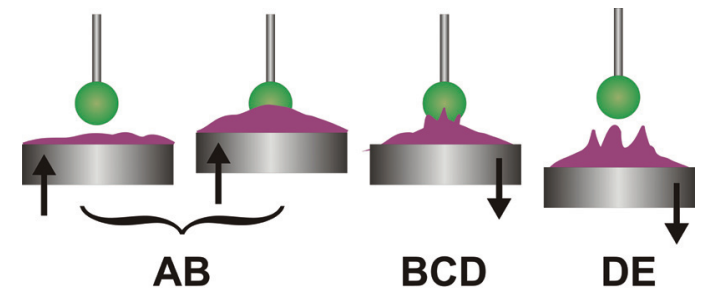

FIGURE 11 - a) Typical load versus deformation curve; b) Progression of forces applied for corresponding graph.

The microforce balance is not indicated for microspheres smaller than $300 \mu \mathrm{m}$, but has the advantage of simulating physiological conditions and providing results at a more microscopic level, besides being more reproducible and sensitive (Mathiowitz, Chickering, Lehr, 1999).

\section{Rheological methods}

This category of methods are all carried out in vitro and were first proposed by Hassan and Gallo (1990), who used viscosimetric assays to macroscopically analyze the formulation-mucin interaction. From this test, it is possible to obtain the mucoadhesion force by monitoring the viscosimetric changes of the system constituted by the mixture of the polymer chosen and mucin. The energy of the physical and chemical bonds of the mucin-polymer interaction can be transformed into mechanical energy or work. This work, which causes the rearrangements of the macromolecules, is the basis of the change in viscosity. A way to analyze the coefficient of viscosity of a hydrophilic dispersion containing mucin plus the mucoadhesive polymer is through the contribution of each component, which results in equation 9:

$\eta_{t}=\eta_{m}+\eta_{p}+\eta_{b}$

where $\eta_{t}$ is the coefficient of viscosity of the system, and $\eta_{m}$ and $\eta_{p}$ are the coefficients of viscosity of mucin and bioadhesive polymer, respectively. The bioadhesion component, $\eta_{b}$, can be obtained from equation 9 , resulting in equation 10 :

$\eta_{b}=\eta_{t}-\eta_{m}-\eta_{p}$

For equations 9 and 10 to be valid, all components should be measured at the same concentration, temperature, time and shear gradient. The bioadhesion force, $F$, is determined by equation 11 :

$F=\eta_{b} \sigma$

where $\sigma$ is the shear gradient.

The main disadvantage of this method is the breakdown of the polymer and mucin network under continuous flow. To avoid this problem, the method was adapted using oscillatory rheology (Callens et al., 2003; Hägerström, 2003). Based on the same assumption that the rheological response of polymer-mucin mixture should be greater than the contributions from the gel and isolated mucin, a parameter called rheological synergism can be obtained. This method is more advantageous than the original, since oscillatory rheology is a non-destructive technique and simultaneously measures viscosity and elastic behavior and can be used to determine mucoadhesion between polymers and mucin (Callens et al., 2003).

The evaluation of rheological synergism can be 
done through two types of oscillatory assays: stress sweep and frequency sweep (Ceulemans, Vinckier, Ludwig, 2002).

In stress sweep, the elastic $\left(\mathrm{G}^{\prime}\right)$ and viscous $\left(\mathrm{G}^{\prime \prime}\right)$ moduli are obtained under constant frequency. This is used to investigate the influence of stress on the dynamic modulus, which should be obtained in the linear viscoelastic region, that is, the region where the material response is characteristic for its microstructure. Above this region, the structure is destroyed. The magnitude of the moduli is a qualitative indication of the system structure. Three situations can be found for polymeric dispersion: $G^{\prime}>G^{\prime}$ ' for a chemically interconnected system, $G^{\prime}>G$ ' for chains with secondary bonds, and $G^{\prime} \leq \mathrm{G}$ " for dispersions with physically-bound molecules. The quantitative measure of rheological synergism $\left(\Delta \mathrm{G}^{\prime}\right)$ can be calculated either in relation to G'or G" (Callens et al., 2003; Ceulemans, Vinckier, Ludwig, 2002), as shown in equation 12.

$\Delta G^{\prime}=G_{\text {mixture }}^{\prime}-\left[G_{\text {polymer }}^{\prime}+G_{\text {mucin }}^{\prime}\right]$

In frequency sweep, stress is maintained constant. The structure of the system can remain intact during the assay if it is conducted in the linear viscoelastic region. Under constant stress and at low frequencies, better structured systems present greater elastic modulus than viscous modulus and both are independent of frequency. On a loglog graph, they are represented by a constant straight line. For less organized systems, dynamic moduli are dependent on the frequency and a slope is observed. (Callens et al., 2003; Ceulemans, Vinckier, Ludwig, 2002).

This test enables analysis of the dynamic viscoelastic parameters corresponding to the same frequency as a function of polymer or mucin concentration, yielding the rheological behavior in relation to the concentration of the system constituents (Hägerström, 2003).

Hägerström (2003) reveals an alternative parameter of rheological synergism, called relative rheological synergism parameter $\left(\Delta G_{\text {relative }}^{\prime}\right)$, calculated from equation 13 and with which it is possible to quantitatively compare the force of polymer-mucin mixture with the isolated polymer:

$\Delta G_{\text {relative }}^{\prime}=\frac{\Delta G^{\prime}}{G_{p}^{\prime}}=\frac{\left(G_{\text {mixture }}^{\prime}-G_{p}^{\prime}\right)}{G_{p}^{\prime}}$

where $\Delta G^{\prime}$ is the rheological synergism, given by the difference between elastic modulus of the mixture $\left(\Delta G_{\text {mixture }}^{\prime}\right)$ and the elastic modulus of the polymer $\left(G_{p}^{\prime}\right)$.

However, $\Delta G_{\text {relative }}^{\prime}$ has the disadvantage of a negative limit up to -1 , while the positive values run to infi- nity. Therefore, the magnitude of positive values cannot be compared with that of negative values. Thus, a new relative parameter was proposed called the logarithmic relation of elastic module $\left(\log G^{\prime}\right)$, which is given by the ratio between elastic modulus of the mixture $\left(G_{m i x}\right)$ and the elastic modulus of the polymer $\left(G_{p}^{\prime}\right)$, as indicated in equation 14.

$\log G^{\prime}=\log \left(\frac{G_{m i x}^{\prime}}{G_{p}^{\prime}}\right)$

This parameter offers the advantage that both positive and negative values have the same magnitude, and are therefore comparable. For instance, the value 1 means that $\mathrm{G}^{\prime}$ of the mixture is 10 -fold greater than that of the isolated polymer (Hägerström, 2003).

Rheological tests are performed totally in vitro and consequently are conducted in combination with the rupture tensile strength test, most frequently used in studies on mucoadhesion. The experimental conditions of both tests differ and there are cases in which the techniques are complementary. Rheology measures the mechanical properties of the system, i.e., the resistance against flow and deformation, assessing the changes the system undergoes in the presence of mucin. However, rheology does not provide any direct information on what occurs at the interface, because the two phases - mucin and polymer - are mixed together prior to the experiment. In the rupture tensile strength test, the interface is artificially created. Even with this difference, when the mucin-polymer produces rheological synergism, a corresponding structure organization is observed at the mucoadhesive interface. The rupture tensile strength test can be applied to solids and semi-solids, while rheology is applicable to semi-solids and liquids. Experimental conditions are critical in the rupture tensile strength test and there are several variables (sample layer, hydration, time of hydration, sample load, time of loading, detachment rate, etc.), which should be optimized and set in order to produce reproducible results. The reproducibility of rheological measures is reasonably good, since the measures are taken on already balanced mixtures; composition, $\mathrm{pH}$, and temperature can be carefully controlled and therefore fewer repetitions are necessary to obtain statistically significant data. Thus, it can be concluded that both methods contribute to different extents toward explaining the mucoadhesive phenomenon, depending on the mucoadhesion mechanism involved, system type, polymer used, etc. (Mathiowitz, Chickering, Lehr, 1999; Hagerstrom, 2003). 


\section{Tests analyzing molecular interactions involved in mucoadhesion}

The general problem arising from methods that show the adhesion force and from the rheological methods is that the mucoadhesive response is seen macroscopically while the interactions occur at a microscopic level.

The use of low frequency dielectric spectroscopy represents an attempt to study gel-mucus interactions near the molecular level. It evaluates the possible physicochemical interactions between molecules and glycoproteins of the mucus at the interface, which is considered the step preceding the formation of bonds during the mucoadhesion process. This technique involves the study of material response to the application of an electrical field. A sinusoidal voltage is applied throughout the sample and the response is measured in function of the frequency. From the responses, the impedance or permittivity of the sample is obtained and the property of charges changing in the system can be determined (Hägerström, 2003). This technique can provide information about the compatibility between mucus and mucoadhesive system by means of the evaluation of the movement of the charged particles. This compatibility is achieved according to the ease with which the particle crosses the barrier between the gel and mucous membrane. The dielectric measures reveal information about the gel and the mucous membrane separately, and about the interface between them (Hägerström, Edsman, Strømme, 2003).

Since the mucoadhesion process can be a consequence of interactions between the mucus layer and the mucoadhesive polymer, it is highly dependent upon the molecular structure, including its charge. It is also well known that glycoproteins molecules, which form the mucus structure, are negative at physiological $\mathrm{pH}$. By means of zeta potential, it is possible to understand the polymer-mucin electrostatic interactions (Takeuchi et al., 2005). The zeta potential of dispersion is defined as the potential between the liquid superficial layer surrounding the dispersed particle and the remaining solution volume. It is a measure of the net surface charge of particles in a dispersed system (Bocataj et al., 2003). In this test, the mucin particles are suspended in an appropriate buffer and mixed with a solution of the polymer. If the addition of the polymer changes the zeta potential value of the mucin particles, this can suggest greater affinity between polymer and mucin particles (Takeuchi et al., 2005).

Another technique being applied to evaluate molecular interactions is the optical biosensor, or resonant mirror biosensor technique. Sigurdsson, Loftsson and Lehr (2006) used this technique to measure the interaction between glycoproteins of the mucus and different polymers. It allows the monitoring of any interaction between two unknown molecules in real time, since one of them can be immobilized with covalent or non-covalent on the system surface while the other remains in solution at the surface. The molecules in solution, when binding to the immobilized molecules, alter the refraction index of the medium and this change is detected by the screening of a laser beam. The results of this study suggested the need for a clearer definition of mucoadhesion, because they called into question the polymers that are swelling dependent and undergo in situ gelification, because they do not seem to interact with glycoproteins, although they are called mucoadhesives (Sigurdsson, Loftsson, Lehr, 2006).

Another test using the same principle, the Biacore test, was applied for the analysis of mucoadhesion by Takeuchi et al. (2005). This test is based on the passage of a mucin suspension through a sensor containing the immobilized polymer. When a mucin particle binds to the polymer at the sensor, both the solute concentration and the refraction index on this surface undergo changes, where the interaction is quantitatively evaluated and reproduced on a diagram. The sensor is a chip with a glass surface covered in a fine gold layer, where functional groups are introduced and the polymer is attached (Takeuchi et al., 2005).

\section{Imaging methods}

Optical microscopes offer insufficient resolution for studying effects at a molecular level. For such investigations, a resolution at micro- or nanometric level is needed. Electronic microscopy gives a larger view, but the environmental conditions in which the sample must be submitted are far from the physiological conditions. For instance, the samples are analyzed in a vacuum chamber and generally are covered with a metallic film to avoid changes caused by the electronic rays (Mathiowitz, Chickering, Lehr, 1999).

Atomic force microscopy (AFM) is a relatively new technique that overcomes such restrictions, because it can be used under any environmental conditions, in air, liquids or vacuum. It enlarges more than $10^{9}$-fold, which enables visualization of isolated atoms and offers a tridimensional image of the surface. The equipment (Figure 12, left side) has a support combined with a probe perpendicularly attached to it. This tip moves toward a plane parallel to the sample, acquiring its topographic characteristics and the tip position is recorded by an optic deflection system: a laser beam is reflected onto the support and its position is then further reflected by a mirror reaching a photodiode sensor. A force-distance curve is plotted to measure the 
forces between this tip and the surface of interest (Mathiowitz, Chickering, Lehr, 1999). This curve is then used in bioadhesion studies. This entails coating the tip in adhesive material, which is generally spherical in shape (Figure 12, right side) and then the interaction with the surface, in this case the mucous membrane, can be measured (Cleary, Bromberg, Magner, 2004).
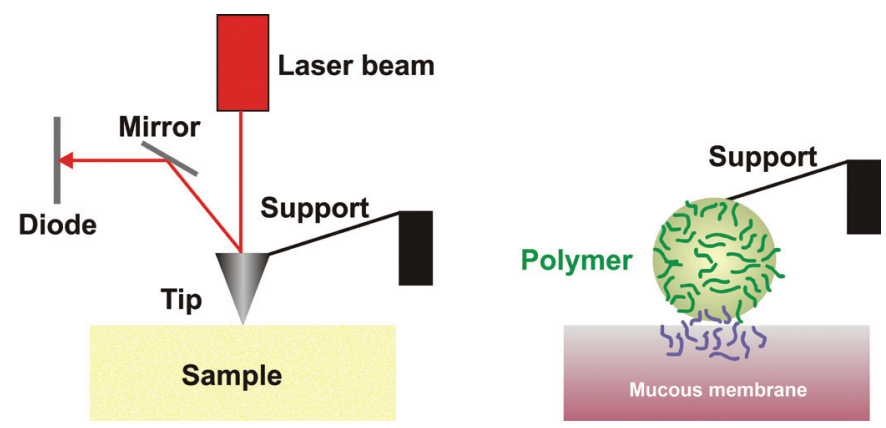

FIGURE 12 - Constituents of AFM and the adaptations made for measuring the adhesive force between polymer and mucus surface. Adapted from Cleary, Bromberg and Magner, (2004), Mathiowitz, Chickering and Lehr (1999).

Besides AFM, there are other techniques using photographic images, such as fluorescence microscopy and confocal laser scanning microscopy (CSLM). Results achieved in ex vivo tests like the non-everted gut sac test (Keely et al., 2005), can be better visualized with this technique. Using radioisotopes or radioactive markers, it is possible to trace the polymer or the substance to be incorporated into the release system, where their location is visualized on the specific microscope, after the excision of the membrane. Takeuchi et al. (2005) used CSLM to analyze liposomes formulated with a fluorescent tracer and administered by the oral route in rats. The intestines were removed at an appropriate time after administration and the retention of the formulation was verified through the images achieved on the confocal microscope.

In the specific case of bioadhesive microspheres, the greater difficulty in their development is the sensitive quantification of the bioadhesive interactions under physiological conditions. Several techniques are being developed to measure the adhesion of great volumes in this kind of sample and others to offer more qualitative data. The previously described microforce balance methodology was an attempt to circumvent this difficulty. In parallel, another technology was developed, Electromagnetic Force-transduction (EFT). In addition to information about bioadhesive forces, this technology also offers the simultaneous video image of the interactions, with high resolution and under physiological conditions. Figure
13 schematically illustrates the technique. The mucous membrane is mounted in a compartment under physiological conditions and the microsphere is positioned directly below the magnetic probe. The compartment is slowly moved down, in an opposite direction to the probe, and the video camera is used to detect sphere movement. According to the movement, the control system increases the magnetic current and the resulting magnetic force $\left(F_{m}\right)$ pulls the sphere to its initial position, separating it from the tissue. After the experiment, the magnetic current is converted into force and the computer calculates the parameters of adhesion. The mucous membrane to be analyzed can be attained after an experiment using an everted gut sac (Mathiowitz, Chickering, Lehr, 1999).

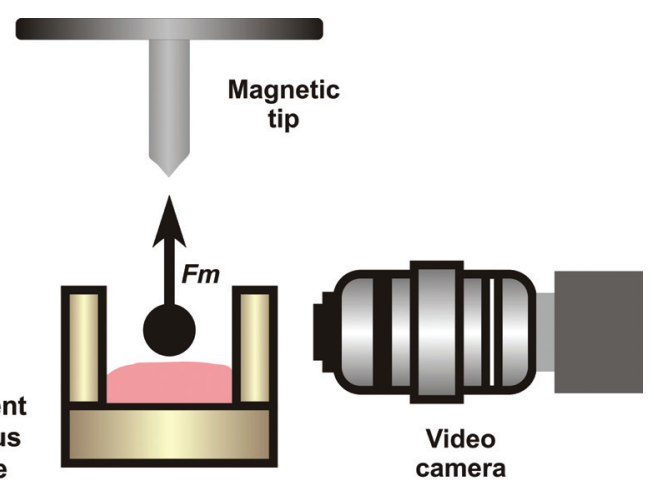

FIGURE 13 - Elements of EFT. Adapted from Mathiowitz, Chickering and Lehr (1999).

An alternative technique which also uses a video camera is the flow-channel method. A fine glass channel is filled with an aqueous bovine submaxillary mucin solution maintained at $37^{\circ} \mathrm{C}$ and humid air is passed through the channel. A particle of the bioadhesive polymer is placed in the mucin gel and both the static and dynamic behaviors are monitored by the camera at frequent time intervals (Ahuja, Khar, Ali, 1997).

\section{Falling Liquid Film Method}

Nielsen, Schubert and Hansen (1998) used a method proposed by Rango Rao and Buri (1989) in which the chosen mucous membrane is placed in a stainless steel cylindrical tube, which has been longitudinally cut. This support is placed inclined in a cylindrical cell with a temperature controlled at $37^{\circ} \mathrm{C}$. An isotonic solution is pumped through the mucous membrane and collected in a beaker (Figure 14). Subsequently, in the case of particulate systems, the amount remaining on the mucous membrane can be counted with the aid of a coulter counter (Chowdary, Rao, 2004). For semi-solid systems, the non adhered 
mucoadhesive can be quantified by high performance liquid chromatography (Nielsen, Schubert, Hansen, 1998). In this later case, porcine stomach, intestinal and buccal mucus were tested, and also jejunum from rabbits. The validation of this method showed that the type of mucus used does not influence the results. The release systems tested were precursors of liquid crystals constituted by monoglycerides. This methodology allows the visualization of formation of liquid-crystalline mesophase on the mucous membrane after the flowing of the fluids and through analysis by means of polarized light microscopy (Nielsen, Schubert, Hansen, 1998).

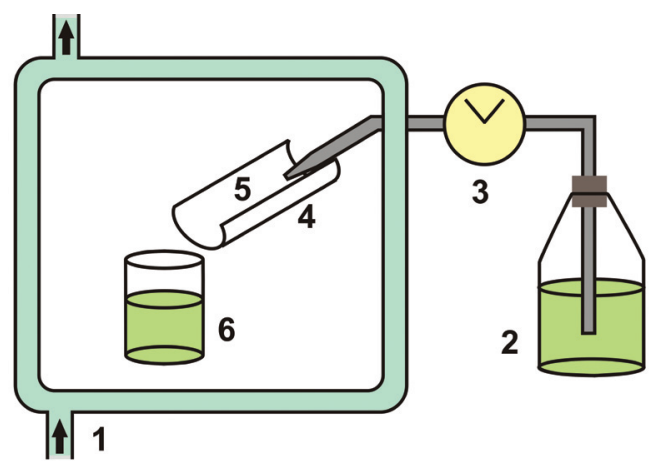

2. Rinsing solution

3. Peristaltic pump
1. Thermostatic bath
4. Stainless steel tube 6. Collection container 5. Biological membrane

FIGURE 14 - Schematic representation of in vitro model used by Nielsen, Schubert and Hansen (1998), adapted from Rango Rao and Buri (1989).

\section{In vivo tests}

There is scant information available on the in vivo behavior of mucoadhesive formulations, especially in humans. Säkkinen et al. (2006) applied gamma scintigraphy to analyze mucoadhesion in vivo of chitosan within the gastrointestinal tract. Gamma scintigraphy allows the immediate visualization of all the formulation transit, with low exposure of the subjects to radiation. The study emphasized the importance of in vivo studies, because although chitosan exhibits an outstanding mucoadhesion capacity in vitro, the retention time at the absorption site in the human gastrointestinal tract was relatively short and not sufficiently reproducible (Säkkinen et al., 2006). The gastrointestinal transit time in animals can also be evaluated in a non-invasive way, in which the release systems can be formulated with opaque radioisotopes and signals can be followed by X-rays, without affecting normal gastrointestinal motility (Chowdary, Rao, 2004).

The number of methodologies applied to analyze mucoadhesion is constantly growing, although the use of different methods may sometimes lead to incoherence among results due to the heterogeneity of parameters and conditions used (Sigurdsso, Loftsson, Lehr, 2006). Ahuja et al. (1997) examined various studies that used the tension resistance method and each had employed different models of mucous membrane and equipment. Despite the large body of evidence obtained to date, further investigations aimed at standardizing the methodologies are warranted.

\section{CONCLUSIONS}

Studies on mucoadhesive systems have focused on a broad array of aspects. It is a growth area whose goal is the development of new devices and more "intelligent" polymers, as well as the creation of new methodologies that can better elucidate the mucoadhesion phenomenon. With the great influx of new molecules stemming from drug research, mucoadhesive systems may play an increasing role in the development of new pharmaceuticals.

\section{ACKNOWLEDGEMENTS}

The authors wish to thank CAPES (Coordenação de Aperfeiçoamento de Pessoal de Nível Superior) for financial support.

\section{REFERENCES}

AHUJA, A.; KHAR, R. K.; ALI, J. Mucoadhesive drug delivery systems. Drug Dev. Ind. Pharm., v.23, n.5, p.489-515, 1997.

ANDREWS, G. P.; JONES, D. S. Rheological characterization of bioadhesive binary polymeric systems designed as platforms for drug delivery implants. Biomacromol., v.7, p.899-906, 2006.

ANDREWS, G. P.; LAVERTY, T. P.; JONES, D. S. Mucoadhesive polymeric platforms for controlled drug delivery, Eur. $J$. Pharm. Biopharm., v.71, n.3, p.505-518, 2008.

BOCATAJ, M.; VOVK, T.; KEREC, M.; DIMNIK, A. D.; GRABNAR, I.; MRHAR, A. The correlation between zeta potential and mucoadhesion strength on pig vesical mucosa. Biol. Pharm. Bull,. v.26, n.5, p.743-746, 2003.

BRAVO-OSUNA, I.; VAUTHIER, C.; FARABOLLINI, A.; PALMIERI, G. F.; PONCHEL, G. Mucoadhesion mechanism of chitosan and thiolated chitosan-poly(isobutiyl cyanoacrylate) core-shell nanoparticles. Biomaterials, v.28, n.13, p.2233-2243, 2007. 
BROMBERG, L.; TEMCHENKO, M.; ALAKHOV, V.; HATTON, T. A. Bioadhesive properties and rheology of polyether-modified poly(acrylic acid) hydrogels. Int. J. Pharm., v.282, n.1, p.45-60, 2004.

BRUSCHI, M. L. Desenvolvimento e caracterização de sistemas de liberação de própolis intrabolsa periodontal. Ribeirão Preto, 2006. 238 p. [Tese de Doutorado. Faculdade de Ciências Farmacêuticas de Ribeirão Preto. Universidade de são Paulo].

BRUSCHI, M. L.; FREITAS, O. Oral bioadhesive drug delivery systems. Drug Ind. Pharm., v.31, n.3, p.293-310, 2005.

BRUSCHI, M. L.; JONES, D. S.; PANZERI, H.; GREMIÃO, M. P. D.; FREITAS, O.; LARA, E. H. G. Semisolid systems containing propolis for the treatment of periodontal disease: in vitro release kinetics, syringeability, rheological, textural, and mucoadhesive properties. J. Pharm. Sci., v.96, n.8, p.2074-2089, 2007.

BRUSCHI, M. L.; JONES, D. S.; PANZERI, H.; GREMIÃO, M. P. D.; FREITAS, O.; LARA, E. H. G. Development and characterization of precursor of liquid crystalline phase with propolis-containing microparticles for use in the treatment of periodontal disease. Drug Develop. Ind. Pharm., v.34, n.3, p.267-278, 2008.

CALLENS, C.; CEULEMANS, J.; LUDWIG, A.; FOREMAN, P.; REMON, J. P. Rheological study on mucoadhesivity of some nasal powder formulations. Eur. J. Pharm. Biopharm., v.55, n.3, p.323-328, 2003.

CEULEMANS, J.; VINCKIER, I.; LUDWIG, A. The use of xantan gum in an ophthalmic liquid dosage form: rheological characterization of the interaction with mucin. J. Pharm. Sci., v.91, n.4, p.1117-1127, 2002.

CHOWDARY, C. P. R.; RAO, Y. S. Mucoadhesive microspheres for controlled drug delivery. Biol. Pharm. Bull., v.27, n.11, p.1717-1724, 2004.

CLEARY, J.; BROMBERG, L.; MAGNER, E. Adhesion of Polyether-Modified Poly(acrylic acid) to Mucin. Langmuir, v.20, n.22, p.9755-9762, 2004.

EVANGELISTA, R. C. Sistemas de liberação controlada de fármacos. Araraquara, 2006. 345 f. [Tese de Livre Docência em Farmacotécnica. Faculdade de Ciências Farmacêuticas. Universidade Estadual Paulista “Júlio de Mesquita Filho"].
FORMARIZ, T. P.; URBAN, M. C. C.; SILVA JUNIOR, A. A.; GREMIÃO, M. P. D; OLIVEIRA, A. G. Microemulsões e fases líquidas cristalinas como sistemas de liberação de fármacos. Rev. Bras. Ciênc. Farm., v.41, n.3, p.301-313, 2005.

GOTO, T.; MORISHITA, M.; KAVIMANDAN, N. J.; TAKAYAMA, K.; PEPPAS, N. A. Gastrointestinal transit and mucoadhesive characteristics of complexation hydrogels in rats. J. Pharm. Sci., v.95, n.2, p.462-469, 2006.

GRABOVAC, V.; GUGGI, D.; BERNKOP-SCHNÜRCH, A. Comparison of the mucoadhesive properties of varios polymers. Adv. Drug Del. Rev., v.57, n.11, p.1713-1723, 2005.

HÄGERSTRÖM, H. Polymer gels as pharmaceutical dosage forms: rheological performance and physicochemical interactions at the gel-mucus interface for formulations intended for mucosal drug delivery. Uppsala, 2003. 76 f. [Dissertation for the degree of Doctor of Philosophy in Pharmaceutics. Uppsala University]

HÄGERSTRÖM, H.; EDSMAN, K.; STRØMME, M. LowFrequency Dielectric Spectroscopy as a Tool for Studying the Compatibility between Pharmaceutical Gels and Mucus Tissue. J. Pharm. Sci., v.92, n.9, p.1869-1881, 2003.

HASSAN, E. E.; GALLO, J. M. A simple rheological method for the in vitro assessment of mucin-polymer bioadhesive bond strength. Pharm. Res., v.7, n.5, p.491-495, 1990.

HUANG, Y.; LEOBANDUNG, W.; FOSS, A.; PEPPAS, N. A. Molecular aspects of muco- and bioadhesion: Tetheres structures and site-specific surfaces. J. Control. Release, v.65, n.1, p.63-71, 2000.

JUNGINGER, H. E.; THANOU, M.; VERHOEF, J. C. Drug Delivery: Mucoadhesive Hydrogels. Encyclopedia of Pharmaceutical Technology (3.ed.). Available at: $<$ http:// www.informaworld.com/smpp/content $\sim \mathrm{db}=\mathrm{all} \sim$ content $=\mathrm{a}$ 758558230 tab $=$ conten $>$. Accessed on: 31 out. 2007.

KEELY, S.; RULLAY, A.; WILSON, C.; CARMICHAEL, A.; CARRINGTON, S.; CORFIELD, A.; HADDLETON, D. M.; BRAYDEN, D. J. In vitro and ex vivo intestinal tissue models to measure mucoadhesion of poly (methacrylate) and N-trimethylated chitosan polymers. Pharm. Res., v.22, n.1, p.38-49, 2005. 
KOCKISCH, S.; REES, G. D.; YOUNG, S. A; TSIBOUKLIS, J.; SMART, J. D. A direct-staining method to evaluate the mucoadhesion of polymers from aqueous dispersion. $J$. Control. Release, v.77, n.1, p.1-6, 2001.

LEE, J. W.; PARK, J. H.; ROBINSON, J. R. Bioadhesive-based dosage forms: The next generation. J. Pharm. Sci., v.89, n.7, p.850-866, 2000.

LEHR, C. M. Lectin-mediated drug delivery: The second generation of bioadhesives. J. Control. Release, v.65, n.1, p.19-29, 2000.

LEUNG, S. H. S.; ROBINSON, J. R. Polymer structure features contributing to mucoadhesion II. J. Control. Release, v.12, n.3, p.187-194, 1990.

MALMSTEN, M. Surfactants and polymers in drug delivery. Drugs and the pharmaceutical Sciences. New York: Marcel Dekker, 2002. 348 p.

MATHIOWITZ, E.; CHICKERING, D. E.; LEHR, C. M. (Eds.). Bioadhesive drug delivery systems: fundamentals, novel approaches, and development. Drugs and the Pharmaceutical Sciences. New York: Marcel Dekker, 1999. $696 \mathrm{p}$.

MORTAZAVI, S. A.; MOGHIMI, H. R. Effect of Surfactant Type and Concentration on the Duration of Mucoadhesion of Carbopol 934 and HPMC Solid Compacts. Ir. J. Pharm. Res., v.2, n.4, p.191-199, 2003.

NAGAI, T. Adhesive topical drug delivery system. J. Control. Release, v.2, p.121-134, p.121-134, 1985.

NAGAI, T.; NISHIMOTO, Y.; NAMBU, N.; SUZUKI, Y.; SEKINE, K. Powder dosage form of insulin for nasal administration. J. Control. Release, v.1, n.1, p.15-22, 1984.

NIELSEN, L. S.; SCHUBERT, L.; HANSEN, J. Bioadhesive drug delivery systems. I. Characterization of mucoadhesive properties of systems based on glyceryl mono-oleate and glyceryl monolinoleate. Eur. J. Pharm. Sci., v.6, n.3, p.231239, 1998.

PARK, J. S.; OH, Y. K.; JUNG, H. Y.; KIM, J. M.; KIM, C. $\mathrm{K}$. In situ gelling and mucoadhesive polymer vehicles for controlled intranasal delivery of plasmid DNA. J. Biomed. Master Res., v.59, n.3, p.144-151, 2001.
PEPPAS, N. A.; HUANG, Y. Nanoscale technology of mucoadhesive interactions. Adv. Drug Del. Rev., v.56, n.11, p.1675-1687, 2004

PEPPAS, N. A.; SAHLIN, J. J. Hydrogels as mucoadhesive and bioadhesive materials: a review. Biomaterials, v.17, n.11, p.1553-1561, 1996.

QIU, Y.; PARK, K. Environment-sensitive hydrogels for drug delivery. Adv. Drug Del. Rev., v.53, n.3, p.321-339, 2001.

RANGO RAO, K. V.; BURI, P. A novel in situ method to test polymers and coated microparticles for bioadhesion. Int. J. Pharm., v.52, n.3, p.265-270, 1989.

SÄKKINEN, M.; MARVOLA, J.; KANERVA, H.; LiNDEVALL, K.; MARTTI MARVOLA, A. A. Are chitosan formulations mucoadhesive in the human small intestine? An evaluation based on gamma scintigraphy. Int. J. Pharm., v.307, v.307, n.2, p.285-291, 2006.

SANTOS, C. A.; JACOB, J. S.; HERTZOG, B. A.; FREESMAN, B. D.; PRESS, D. L.; HARNPICHARNCHAI, P.; MATHIOWITZ, E. Correlation of two bioadhesion assays: the everted sac technique and the CAHN microbalance. $J$. Control. Rel., v.61, n.2, p.113-122, 1999.

SHIN, S. C.; LEE, J. W.; YANG, K. H.; LEE, C. H. Preparation and evaluation of bioadhesive benzocainegels for enhanced local anesthetic effects. Int. J. Pharm., v.260, n.1, p.77-81, 2003.

SIGURDSSON, H. H.; LOFTSSON, T.; LEHR, C. M. Assessment of mucoadhesion by a resonant mirror biosensor. Int. J. Pharm., v.325, n.1, p.75-81, 2006.

SMART, J. D. The basics and underlying mechanisms of mucoadhesion. Adv.Drug Del. Rev., v.57, n.11, p.15561568, 2005.

TAKEUCHI, H.; THONGBORISUTE, J.; MATSUI, Y.; SUGIHARA, H.; YAMAMOTO, H. H.; KAMASHIMA, Y. Novel mucoadhesion tests for polymers and polymercoated particles to design optimal mucoadhesive drug delivery systems. Adv. Drug Del. Rev., v.57, n.11, p.15831594, 2005.

VYAS, T. K.; BABBAR, A. K.; SHARMA, R. K.; SINGH, S., MISRA, A.; Preliminary brain-targeting studies on intranasal mucoadhesive microemulsion of sumatriptan. AAPS Pharm. Sci. Tech., v.7, n.1, p.E1-E9, 2006. 
WISE, D. L. Handbook of pharmaceutical controlled release technology. New York: Marcel Dekker, 2000. 890 p.

WITTAYA-AREEKUL, S.; KRUENATE, J.; PRAHSARN, C. Preparation and in vitro evaluation of mucoadhesive properties of alginate/chitosan microparticles containing prednisolone. Int. J. Pharm., v.312, n.1, p.113-118, 2006.
WONG, C. F.; YUEN, K. H.; PEH, K. K. An in-vitro method for buccal adhesion studies: importance of instrument variables. Int. J. Pharm., v.180, n.1, p.47-57, 1999.

WOODLEY, J. Bioadhesion, new possibilities for drug administration? Clin. Pharmacokinet., v.40, n.2, p.77-84, 2001.

Received for publication on $20^{\text {th }}$ April 2008

Accepted for publication on $17^{\text {th }}$ June 2009 
